\title{
Pre-extension Demonstration of Improved Teff Variety (Dagim) at Ambo and Dandi Districts of West Shoa Zone, Oromia Region, Ethiopia
}

\author{
Yenenesh Duguma, Dawit Milkias* \\ Ethiopian Institute of Agricultural Research (EIAR), Ambo Agricultural Research Center, Ambo, Ethiopia
}

Email address:

mkdave04@gmail.com (D. Milkias)

${ }^{*}$ Corresponding author

\section{To cite this article:}

Yenenesh Duguma, Dawit Milkias. Pre-extension Demonstration of Improved Teff Variety (Dagim) at Ambo and Dandi Districts of West Shoa Zone, Oromia Region, Ethiopia. International Journal of Agricultural Economics. Vol. 6, No. 5, 2021, pp. 208-211.

doi: $10.11648 /$ j.ijae.20210605.11

Received: August 23, 2021; Accepted: September 10, 2021; Published: September 26, 2021

\begin{abstract}
The activity was conducted for two consecutive years, 2019 and 2020 cropping season at Ambo and Dandi districts of West Showa Zone with the objective to evaluate for grain yield, yield related traits and farmers' perception or preference and the performance of improved teff variety along with recommended package. Sites were selected based on teff production potential of the area. Two districts and three PAs from each district and eighteen target farmers were purposively selected on the ground that they are the leading producer of teff in the area. Training was given for farmers, Development Agents and experts on production of improved teff technologies from site selection up to postharvest practices of improved teff variety. Quantitative data such as yield data was collected and analysed using SPSS, whereas farmers feedback were analysed qualitatively. Recommended seed and fertilizer rate were used for the demonstration trial establishment. According to the result of Dagim variety, mean grain yield $18.79 \mathrm{qt} / \mathrm{he}$ and $25.51 \mathrm{qt} / \mathrm{he}$ were recorded in Ambo and dendi districts respectively. Thus, Dagim variety is recommended for further scaling up activities at Ambo and Dendi districts taking into consideration of its productivity. Farmers of those areas should use the variety in order to increases their teff production and enhance their income from teff.
\end{abstract}

Keywords: Demonstration, Teff, Yield, Dagim Variety

\section{Introduction}

Agriculture contributes $34.1 \%$ to the GDP, employs some $79 \%$ of the population, accounts for $79 \%$ of foreign earnings, and is the major sources of raw material and capital for investment and market [15]. More than $80 \%$ of the Ethiopian population earns their livelihood from crop cultivation and livestock rearing activities. Crop production is a major contributor to Gross Domestic Product from the sub sectors of agriculture. Among the crops, coffee, pulses, oilseeds, potatoes, sugarcane, vegetables and cereals are principal crops grown in Ethiopia [9]. As a result, teff is the most important cereal crop in terms of both production and consumption in Ethiopia [1].

Cereals are the major food crops both in terms of the area coverage and volume of production and accounts for $95 \%$ of agricultural production in Ethiopia and contributed $86.68 \%$ of the grain production [6]. Maize, wheat, and teff are the most important cereals in terms of volume, accounting for a total of $77 \%$ of all cereal production [2], while maize, teff, wheat and sorghum have made $26.80 \%, 16.76 \%, 15.81 \%$ and $16.20 \%$ of the grain production respectively [5]. From the cereal crops, Teff is the most preferred staple food by majority of the Ethiopian population and its center of origin is in Ethiopia. Teff has high energy, phosphorus, and calcium and iron contents [8]. Moreover, the economic contribution of teff indicates that real Teff output on average accounted for $6.1 \%$ of the real GDP, while growth in real Teff output accounted for $6.4 \%$ of the total growth in real GDP i.e., $0.67 \%$ of the 10.7 percent growth in real GDP [7].

Teff (Eragrostis teff) is endemic to Ethiopia and its major diversity is found only in that country. It is a nutritious small 
grained cereal, related to millet, there is no doubt that it is a very ancient crop in Ethiopia and domesticated by Ethiopian farmers between 3 and 6 millennia ago [10]. Teff is produced in five regions of Ethiopia in Tigray, Amhara, Oromia, SNNPR, and Benishangul Gumuz. However, grown mainly in Amhara and Oromia. It is reported that these two regions produced along about $85 \%$ of the total cultivation land of teff and $87 \%$ of production share of teff in the country during 2014/2015 production year [5].

Ecologically, teff is adapted crop in the diverse agroecological areas of Ethiopia and grows well under stress environments better than wheat, barley and other cereals known world-wide [11]. It tolerates low moisture conditions and often considered as a rescue crop that survives and grows well in the season when early planted crops fail due to moisture stress. Because of this, it is said to be a "low-risk" crop for farmers [3].

In Ethiopia, teff is traditionally grown as a cereal crop. The grain is ground to flour, which is mainly used for making enjera, make local alcoholic drinks called Tela and Katikala and sometimes for making porridge. The west product of tef called straw, besides being the most important feed for cattle and also used to reinforce mud for construction of house purpose [12]. Teff has both cultural and economic value for Ethiopian farmers. In recent days, it is among the cash crops and has been attracting an export market due to its nutritional value and owing to its high mineral content, has started to be used in mixtures with soybean, chickpea and other grains in the baby food industry [4].

In West Showa, teff is the main crop produced by the majority of smallholder farmers. Usually, the crop is sown in this area early July up to end of this month and November December harvested. The crop is produced for both household consumption and cash crop. In this area the straw of teff is also used for construction of house and used as the main feed resource for cattle. Despite the yield of the crop is low in the area of West Shoa Zone due to lack of improved seed and low application of the recommended packages of teff. To over-come these problems demonstration of improved teff variety was initiated.

To this end, in 2019-2020 production seasons, participatory variety selection trial was conducted in the West Showa zone, Ambo and Dendi Districts Ethiopia, using newly released teff variety called Dagim and well-known local teff variety. Therefore, this study was proposed with an objectives of demonstrating and promoting improved variety of teff, evaluating the performance of improved teff variety along with management practices under farmers' perception and to enhance awareness of farmers about newly released teff variety in the study area.

\section{Material and Methods}

\subsection{Description of the Study Areas}

The demonstration was conducted at Ambo and Dandi districts of West Shoa Zone for two consecutive cropping seasons. Ambo district is one of West Shoa Zone districts a distance $120 \mathrm{~km}$ from Addis Ababa and capital city of the zone. Ambo District is found in altitude 2106 m.a.s.l and ( $8^{\circ} 59^{\prime} \mathrm{N}$ latitude and $37^{\circ} 51^{\prime} \mathrm{E}$ longitude). The temperature of the district ranges from 11 to $26^{\circ} \mathrm{C}$ with average annual rainfall of $1012 \mathrm{~mm} /$ year and major soil type of the District is Verti (silt) soil with Black color.

Dendi is one of district part of the West Shoa Zone. The annual rainfall of district $1078 \mathrm{~mm}$ /year and altitude 2278 m.a.s.l. It has a mean maximum and minimum temperature ranges of $10^{\circ} \mathrm{C}$ and $24^{\circ} \mathrm{C}$ respectively. Major areas of district soil type Vertisol/silt soil with deep black and certain areas brown color [13].

\subsection{Site and Farmers Selection}

Two districts and three PAs from each district and eighteen target farmers were purposively selected on the ground that they are the leading producer of teff in the area. Three PAs from Ambo district and three PAs from Dendi were selected based on their production potential. Farmer's research and extension group (FREG) approach was followed to select farmers and group under trial farmers.

A total of 2 FREG's were organized having 22 male and 4 female members. Among the FREG member a total of eighteen (18) interested trial farmers were selected in both districts. The trial farmers were selected based on their willingness to contribute a land size of $2500 \mathrm{~m}^{2}$ per variety. Packaged production technologies (seed rate, seed treatment, spacing, fertilizer management and weed management) recommended for teff production were used. Plots were kept free of weeds.

Table 1. Demonstration site, farmers and plot size.

\begin{tabular}{llll}
\hline \multirow{2}{*}{ District } & $\begin{array}{l}\text { Peasant } \\
\text { Association (PA) }\end{array}$ & $\begin{array}{l}\text { Number of selected } \\
\text { HHs }\end{array}$ & Area (he) \\
\hline \multirow{3}{*}{ Ambo } & Amaro & 3 & \\
& Bayo korbi & 3 & 4.5 \\
& Gosu kora & 3 & \\
\multirow{2}{*}{ Dendi } & Faji Gelila & 3 & 4.5 \\
& Yubdo & 3 & \\
& Lokloka & 3 & 9 \\
\hline
\end{tabular}

Source: Own data 2020.

\subsection{Planting Materials and Design Used}

One newly released and adaptable teff varieties (Dagim vs Local) were used. Planting materials (Seed) were acquired in advance from Debrezeit Agricultural Research Center and local variety from selected farmers in the study area. The land used for two varieties were total gross area (block) $2500 \mathrm{~m}^{2}$ for each farmer; $50 \times 50 \mathrm{~m}$ plot length, row spacing $0.2 \mathrm{~m}$ and $1 \mathrm{~m}$ spacing between plots.

\subsection{Data Collection}

Grain yield, Farmers' feedbacks and costs and income gained involved were collected [14]. The grain and economic data were collected using data collection sheets. The 
feedbacks were collected using checklist by conducting group discussions and key informant interviews. Regular follow-up and interaction with farmers, personnel interview, observation and farmers' preference were used to collect the data.

Variety preference ranking: The variety preference ranking was conducted using group discussions. The farmers were let to observe and set selection criteria at the maturity stage of the crop. The selected criteria were then used to select the preferred variety.

Data analysis Method: Descriptive statistics were used to analyze the yield data. Pair wise ranking was used for traits of demonstrated varieties and simple ranking method was used to compare varieties.

\section{Results and Discussion}

\subsection{Vield Performance of Demonstrated Technology}

Dagim variety with local check was demonstrated at six (6) Kebeles of two Districts checked for two consecutive years. Single plot design $(50 \times 50 \mathrm{~m})$ was used, $25 \mathrm{~kg} / \mathrm{ha}$, $100 \mathrm{~kg} / \mathrm{ha}$ and $100 \mathrm{~kg} / \mathrm{ha}$ used Seed, NPS and Urea respectively. The result of teff variety demonstration revealed that, the newly released Dagim variety performed better than the standard check local variety at all demonstration sites. Accordingly, Dagim variety gave higher yield (18.79 qt/he in Ambo District and $25.51 \mathrm{qt} / \mathrm{he}$ at Dendi district than local variety which gave an average 14.86 in Ambo and 14.81qt/he at Dendi district.

Table 2. Main grain yield.

\begin{tabular}{llll}
\hline Variety & Ambo & Dendi & Overall mean \\
\hline Dagim & 18.79 & 25.51 & 18.79 \\
Local Check & 14.86 & 15.88 & 14.81 \\
\hline
\end{tabular}

Source: Own data 2020.

Yield data per plot accepted by targeted farmers. At the side of yield data, as preference of farmers' Dagim variety higher yield than local check by early maturity and very white in color. Dagim variety was preferred by farmers' because of, the cane has strong and more straw than locally and very white in color this is also best for attracting beneficiary and increase demand of teff its quality, very white in color increase the demands and increase income of farmers than other variety of teff. In Ethiopia in general and in most areas of West Showa zone specifically white teff (locally called Magna teff) injera also used for holidays and occasions.

\subsection{Capacity Development}

\subsubsection{Training}

Table 3 shows the number of farmers, development agents, district office of agriculture experts and other participants who attended training related with teff production and management before starting the activity. Totally 26 participants attended the training.
Table 3. Number of participated trainings.

\begin{tabular}{llll}
\hline \multirow{2}{*}{ Issue of training } & \multicolumn{2}{l}{ Number of participants } & M \\
\cline { 2 - 4 } & & F \\
\hline \multirow{2}{*}{ Teff production and } & Farmers & 11 & 7 \\
managements & Development agents & 3 & 1 \\
& Experts & 2 & 2 \\
& Total & 16 & 10 \\
\hline
\end{tabular}

Source: Own data 2020.

Training was given for participating farmers, DAs and Agricultural experts on the agronomic practices of teff and opportunities of demonstration improved teff variety. Follow up; technical support and super vision were done. And, evaluate periodically the performance of improved newly released variety by method of Participatory technology evaluation. Field day was conducted at both Districts. So that, results and information about teff demonstration was communicated among participating farmers from all targeted kebeles. During the perception of farmers, DAs, agricultural office experts and other stakeholders were very satisfied by observing the demonstrated Dagim variety as compared to local variety and raise their demanded for these technologies furthers pre-scaling up and scaling up activities. Beside demonstration of these tef technologies observation was enhanced the linkage between research center and agricultural offices as many agricultural problems.

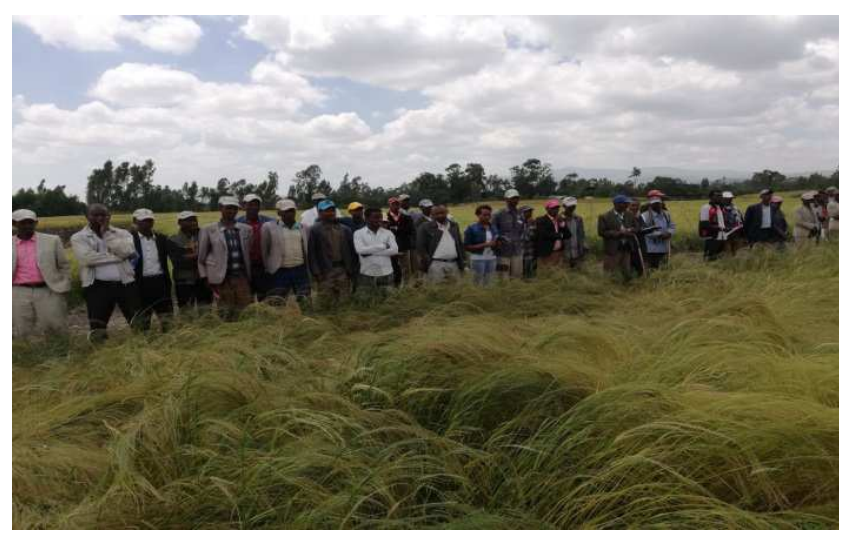

Figure 1. Field day conducted at Dandi district, Lokloka Aba kebele.

Teff is multipurpose crop in West Shoa Zone as household consumption, as cash crop and the straw is used for construction house with making mud and best feed for cattle. Finally, motivation and attracting of farmers high to expand and produce Dagim teff improved variety.

\subsubsection{Farmers'Preference on Demonstration}

Farmers' preferences are most key elements for technology varieties selection and expanded. On this demonstration, higher yield of teff variety (Dagim) increases their motivation to grow recommended and improved teff variety. Participants of farmers raised their preference used by the below criteria:- 
Table 4. Rank of the varieties based on farmers' selection criteria.

\begin{tabular}{lll}
\hline Preference & Dagim & Local check \\
\hline Yield & High & Lower \\
Maturity & Early & Late \\
Tolerance to disease & Tolerate & Not at all tolerant \\
Lodge & Not lodge & At some place lodge \\
Grain color & Very white & Mixed \\
Straw & Strong and more straw & Few straw \\
\hline
\end{tabular}

Source: Own data 2020.

\section{Conclusion and Recommendations}

This demonstration was conducted at Ambo and Dendi districts of west Showa zone in 2019 and 2020 cropping seasons. The results indicated that the demonstrated variety gave promising yield having an average $18.79 \%$ yield advantage over farmers' variety. Moreover, the variety is profitable with an average return greater than the check in two production season. In terms of farmer's preference, Dagim variety was selected as first choice by the participating farmers based different level of agreements and got acceptance than local variety due to high yielder, early mature and very white in color. Therefore, Dagim is recommended for further scaling up to increases teff production and productivity in the area. Farmers of those areas should use the improved variety in order to increases their teff production and enhance their income from teff.

\section{References}

[1] Annual report Ministry of Agricultural and Rural development, 2006.

[2] ATA (Agricultural Transformation Agency). 2016. Transforming agriculture in Ethiopia. Annual report 2015/2016.

[3] Adera Sisay 2016, Response of Tef (Eragrostis tef) to Different Blended Fertilizer Rates on Vertisols in Jama District, North eastern Ethiopia. M.Sc Thesis Summited Haramaya University, Haramaya.

[4] Annual crop Variety registered book of 2016, Ministry of Agriculture, Addis Ababa, Ethiopia.
[5] Central Statistical Agency (CSA, 2015). Agricultural sample survey report on area and production of major crops, 1, Addis Ababa.

[6] Dawit Milkias. Factors Affecting High Yielding Teff Varieties Adoption Intensity by Small Holder Farmers in West Showa Zone, Ethiopia.

[7] Fantu, 2015: Summary of ESSP Working Paper 89, Productivity and efficiency of small holder Teff farmers in Ethiopia.

[8] Fufa Bekabil, et al, 2011. "Strengthening the teff value chain in Ethiopia." Mimeo, Agricultural Transformation Agency (ATA), Addis Ababa, Ethiopia.

[9] Kebede B, Korji D, Amare G (2018) Participatory Evaluation and Selection of Improved Haricot bean Varieties at Liben District, Lowland Agro Ecology of Guji Zone, Oromia Regional State, Ethiopia. Adv Crop Sci Tech 6: 332. doi: $10.4172 / 2329-8863.1000332$.

[10] Samuel, G and Sharp, K., 2008. Commercialization of smallholder agriculture in selected Tef-growing areas of Ethiopia.

[11] Refissa Leta. 2012. Effects of sowing methods and fertilizer types on yield and yield components of tef (Eragrostis tef) at Guduru woreda, Western Oromia, Ethiopia. M.Sc. thesis, Haramaya University, Haramaya, Ethiopia.

[12] Taha Mume, Tilahun Geneti, Dagnachew Lule, Tesfaye Gemechu, Fekede Gemechu, Ahimed Mohammed, Tesfaye Alemu, Kefyalew Assefa, Samuel Tufa, Tilahun Chibsa and Tilahun Geleto (eds), 2019. Oromia Agricultural research institute workshop proceeding on pre-extension demonstration of Agricultural Technologies, 26-29 June 2019, Addis Ababa, Ethiopia.

[13] Woreda Office of Agriculture and rural development 2020: Unpublished annual report.

[14] Basha Kebede and Dembi Korji (2017). Demonstration of improved teff varieties at selected midland districts of Guji zone, Oromia regional state, Ethiopia. Asian Journal of Agriculture and Rural Development, 7 (7), 131-135.

[15] Ministry of Agriculture (MOA). (2019). Transforming Ethiopian Agriculture: Power Point Presentation, Briefing for Agricultural Scholar Consultative Forum, April 2019, Addis Ababa. 